\title{
Percepção de mães de crianças autistas sobre o isolamento social motivado pela pandemia do Covid-19
}

\author{
Leila Maria de Andrade Filgueira ${ }^{1}$ e Aline Veras Morais Brilhante ${ }^{1}$ \\ 1 Programa de Pós-Graduação em Saúde Coletiva da Universidade de Fortaleza, Brasil | \\ leila_filgueira@hotmail.com; alineveras@unifor.br | https://orcid.org/0000-0002-2210- \\ 4498;https://orcid.org/0000-0002-3925-4898
}

\begin{abstract}
Resumo: Introdução: A pandemia do covid-19 gerou um contexto ansiogênico para pessoas autistas. Objetivo: Analisar os efeitos do isolamento social associado ao controle pandêmico sobre a vida de familiares cuidadores de crianças autistas. Método: Trata-se de uma pesquisa qualitativa realizada no período de abril a maio de 2020, com 14 mães com idades entre 28 e 47 anos e um pai com 34 anos. A coleta dos dados foi realizada por entrevistas semiestruturadas realizadas por meios digitais. Os dados foram analisados segundo a análise temática de conteúdo, partindo do paradigma da Neurodiversidade. Resultados: Do processo de análise emergiram três categorias: magnificação das questões de gênero durante a pandemia, anseios relacionados ao processo terapêutico da criança e resiliência e religiosidade. Conclusão: Conclui-se que a pandemia potencializou desigualdades de gênero, culminando no desgaste físico, psíquico e emocional dessas mulheres. Atrelada a essas questões, emerge a preocupação com prejuízos no desenvolvimento dos filhos. Esses anseios, amplificam a auto responsabilização dessas mulheres, culminando em um sentimento de culpa que encontra amparo na religiosidade como principal estratégia de enfrentamento.
\end{abstract}

Palavras-chaves: Covid-19; Autismo; Gênero.

Mother's Perception of Autistic Children on Isolation Motivated by the Pandemic of Covid-19

Abstract: Introduction: The covid-19 pandemic created an anxiogenic context for autistic people. Objective: To analyze the effects of social isolation associated with pandemic contro on the lives of family caregivers of autistic children. Method: This is a qualitative research carried out from April to May 2020, with 14 mothers aged between 28 and 47 years and a father aged 34 years. Data collection was carried out through semi-structured interviews carried out by digital means. Data were analyzed according to thematic content analysis, based on the paradigm of Neurodiversity. Results: Three categories emerged from the analysis process: magnification of gender issues during the pandemic, concerns related to the child's therapeutic process, and resilience and religiosity. Conclusion: It is concluded that the pandemic potentiated gender inequalities, culminating in the physical, psychological and emotional wear of these women. Linked to these issues, the concern with damage to the development of children emerges. These anxieties amplify the self-responsibility of these women, culminating in a feeling of guilt that finds support in religiosity as the main coping strategy.

Keywords: Covid-19; Autism; Gender.

\section{Introdução}

O enfrentamento da crise sanitária associada à pandemia do COVID-19 demandou uma série de mudanças comportamentais. Entre estas, o distanciamento social - e, em muitos casos, o isolamento social rígido - vigoraram desde o princípio, assumindo um papel relevante no controle da pandemia, principalmente no período que antecedeu à vacinação em massa (WHO, 2021). Aparte da inquestionável relevância destas medidas, elas culminam em drásticas alterações de rotina, gerando um contexto ansiogênico para pessoas autistas (Colizzi et al., 2020).

Embora o autismo congregue pessoas com diferentes necessidades de suporte, algumas características são comuns à maioria das pessoas no espectro, dentre as quais podemos listar: déficits na interação social, comprometimento da comunicação e da linguagem, padrões de comportamentos repetitivos e rigidez na realização dos hábitos diários (Lord et al., 2018). 
A manutenção de uma rotina previsível é defendida, tanto por especialistas como por autistas, como uma estratégia importante para controle da ansiedade e desenvolvimento da autonomia (Amorim et al., 2020; Courtenay \& Perera, 2020). No entanto, a necessidade do distanciamento e/ou isolamento social rígido, bem como a emergência contínua de novas recomendações de biossegurança, comprometeu a previsibilidade como estratégia comportamental de assistência a pessoas autistas (Amorim et al., 2020). Além disso, essas medidas podem potencializar as dificuldades de socialização e culminar em retrocessos nas interações sociais que porventura tenham sido conquistadas (Amorim et al., 2020; Colizzi et al., 2020).

No Brasil, as questões supramencionadas vêm agravar um contexto crônico de exclusão sistemática e estrutural de pessoas autistas. Apesar da publicação da Política Nacional de Proteção dos Direitos da Pessoa com Transtorno do Espectro Autista em 2012 (Lei no $12.764,2012)$, a inclusão no país ainda é insipiente, restringindo-se à presença do aluno na escola, sem as necessárias adaptações psicopedagógicas, além da ausência de outras medidas de inclusão social-educacional e de uma esparsa rede de assistência terapêutica (Bialer, 2015). Nesse contexto, as consequências sociais da pandemia se sobrepõem a uma estrutura com esparsa rede de apoio tanto para pessoas autistas como para seus familiares (Amorim et al., 2020; Colizzi et al., 2020).

A partir dessas constatações, deu-se início a uma ampla pesquisa sobre os efeitos da pandemia em diferentes aspectos da vida de pessoas autistas (nos diferentes ciclos de vida) e de seus familiares. $O$ artigo aqui apresentado contempla um braço da pesquisa, a saber, os efeitos do contexto pandêmico na vida de cuidadores e familiares de crianças autistas. Essa etapa partiu dos seguintes questionamentos: Quais os efeitos do distanciamento ou isolamento social na vida de cuidadores de crianças autistas? Como cuidadores e familiares percebem os efeitos do distanciamento ou isolamento social na vida de crianças autistas? Quais estratégias e redes de apoio emergiram ou se fortaleceram nesse contexto?

Deste modo, este estudo objetiva analisar os efeitos do isolamento social associado ao controle pandêmico sobre a vida de familiares cuidadores de crianças autistas.

\section{Metodologia}

Trata-se de uma pesquisa de natureza qualitativa realizada com familiares de crianças autistas, no período de abril de 2020 a maio de 2020 . Os participantes foram recrutados pelo método bola de neve onde o primeiro sujeito indica o segundo e assim sucessivamente (Vinuto, 2014). O recrutamento iniciou-se a partir da presidente de uma associação de familiares de pessoas autistas, que indicou a próxima participante e assim por diante. Antes da indicação, eram esclarecidos os critérios de inclusão. Os convites foram enviados por aplicativos de mensagem. Das pessoas convidadas, três não responderam ou se recusaram a participar da pesquisa. Diante da ausência de resposta ou da recusa, retornávamos ao participante anterior, solicitando uma nova indicação. $O$ recrutamento seguiu desta forma até a saturação dos dados, pormenorizada adiante.

Os critérios de inclusão foram: ter idade maior que 18 anos e ser mãe ou pai de criança autistas com até 12 anos de idade incompletos. Considerou-se critério de exclusão a impossibilidade de realização da entrevista de forma remota, por celular ou computador. Vale ressaltar que a pesquisa ocorreu durante o período de isolamento social rígido no município, o que impossibilitou as entrevistas presenciais. Participaram 14 mães com idades entre 28 e 47 anos e um pai com 34 anos, residentes em municípios integrantes da Região Metropolitana de Fortaleza. 
A coleta dos dados foi realizada por entrevistas semiestruturadas, cujo roteiro foi composto por quatro perguntas amplas, que buscavam caracterizar os efeitos da pandemia e do isolamento sobre as crianças, da pandemia e do isolamento sobre as famílias, as dificuldades enfrentadas pelos pais durante o período de isolamento social e as estratégias de enfrentamento utilizadas. As entrevistas foram realizadas por videoconferência utilizando-se o aplicativo WhatsApp Messenger.

Após cada entrevista e respectiva transcrição, as duas pesquisadoras imergiram no material, registrando suas análises individuais, que foram então compiladas em temas e pré-categorias. Estas, por sua vez, foram organizadas em tabelas, permitindo a constatação visual da saturação (Fontanella et al., 2011), o que permitiu a interrupção do recrutamento das mães $14^{\mathrm{a}}$ entrevista. Apenas um pai aceitou participar da pesquisa, tendo-se convidado outros três pais que ou não responderam ou recusaram formalmente. Consideramos essa uma fragilidade deste estudo. Ainda assim, a entrevista deste único participante do gênero masculino permitiu ratificar achados importantes obtidos a partir das entrevistas das mães.

Os dados foram analisados segundo a análise temática de conteúdo (Minayo, 2014), partindo do paradigma da Neurodiversidade como suporte teórico. As entrevistas foram transcritas e o material foi organizado e sistematizado, a fim de se identificar os temas recorrentes. Esses temas foram agrupados em núcleos temáticos e posteriormente em categorias como exposto na tabela 1. A análise e categorização foi realizada por duas pesquisadoras independentes, havendo o pareamento das análises para o processo final de categorização.

Tabela 1. Temas, núcleos temáticos e categorias analíticas.

\begin{tabular}{|c|c|c|}
\hline Temas & $\begin{array}{l}\text { Núcleos } \\
\text { Temáticos }\end{array}$ & Categorias \\
\hline $\begin{array}{l}\text { Divisão sexual } \\
\text { das atividades } \\
\text { domésticas }\end{array}$ & $\begin{array}{l}\text { Sobrecarga } \\
\text { materna imposta }\end{array}$ & $\begin{array}{l}\text { Magnificação } \\
\text { das questões de } \\
\text { gênero durante } \\
\text { a pandemia }\end{array}$ \\
\hline \multicolumn{3}{|l|}{$\begin{array}{l}\text { Agravamento do } \\
\text { acúmulo de } \\
\text { funções } \\
\text { maternas }\end{array}$} \\
\hline $\begin{array}{l}\text { Sobrecarga } \\
\text { autoimposta }\end{array}$ & \multirow{3}{*}{$\begin{array}{l}\text { Construções } \\
\text { identitárias } \\
\text { sobre o "ser } \\
\text { mulher" e o "ser } \\
\text { mãe" }\end{array}$} & \\
\hline Culpa materna & & \\
\hline $\begin{array}{l}\text { Conflitos na } \\
\text { conciliação } \\
\text { entre trabalho e } \\
\text { maternagem }\end{array}$ & & \\
\hline $\begin{array}{l}\text { Medo de } \\
\text { retrocessos } \\
\text { terapêuticos }\end{array}$ & $\begin{array}{ll}\text { Receio } & \text { de } \\
\text { retrocessos } & \\
\text { diante } & \text { da }\end{array}$ & $\begin{array}{l}\text { Anseios } \\
\text { relacionados ao } \\
\text { processo }\end{array}$ \\
\hline $\begin{array}{l}\text { Medo de } \\
\text { retrocessos } \\
\text { pedagógicos }\end{array}$ & $\begin{array}{l}\text { interrupção dos } \\
\text { processos } \\
\text { terapêuticos }\end{array}$ & ter \\
\hline $\begin{array}{l}\text { Dificuldades de } \\
\text { adaptação } \\
\text { escolar no } \\
\text { modelo remoto }\end{array}$ & & \\
\hline
\end{tabular}




\begin{tabular}{|c|c|c|}
\hline Temas & $\begin{array}{l}\text { Núcleos } \\
\text { Temáticos }\end{array}$ & Categorias \\
\hline \begin{tabular}{lr}
\multicolumn{3}{l}{ Acomodação } \\
das dificuldades \\
de socialização \\
diante \\
demandas das \\
isolamento
\end{tabular} & $\begin{array}{l}\text { Receio de } \\
\text { acomodação ou } \\
\text { agravamento } \\
\text { das dificuldades } \\
\text { de socialização }\end{array}$ & \\
\hline $\begin{array}{l}\text { Consolo na fé e } \\
\text { na religiosidade }\end{array}$ & $\begin{array}{l}\text { Religiosidade } \\
\text { como meio para } \\
\text { fortalecimento } \\
\text { da resiliência }\end{array}$ & $\begin{array}{l}\text { Religiosidade } \\
\text { resiliência }\end{array}$ \\
\hline $\begin{array}{l}\text { Busca de } \\
\text { esperança na fé } \\
\text { e } \\
\text { religiosidade na }\end{array}$ & & \\
\hline
\end{tabular}

A fim de assegurar o anonimato das participantes, estas receberam o pseudônimo de letras alfabéticas seguidas de numeração arábica (A1, A2, A3...). O estudo atendeu à Resolução 510/2016, sobre a Ética na Pesquisa na área de Ciências Humanas e Sociais e foi aprovado pelo Comitê de Ética e Pesquisa da Universidade de Fortaleza, sob o número 435/2011.

\section{Resultados e Discussão}

Do processo de análise dos relatos obtidos, emergiram três categorias: Magnificação das questões de gênero durante a pandemia, anseios relacionados ao processo terapêutico da criança e resiliência e religiosidade.

\subsection{Magnificação das Questões de Gênero Durante a Pandemia}

Dentre os efeitos da pandemia e do isolamento social sobre as famílias, destacou-se a magnificação de questões de gênero já existentes. As participantes, que já acumulavam função de trabalho externo e cuidados domésticos, passaram a ter que integrar essas atividades na mesma ambiência:

"Além do trabalho online e do cuidado com as crianças, assumi a rotina da casa [...]. De manhã eu atendo [virtualmente]. À tarde me organizo em relação à casa e às crianças, tendo um momento de fazer as tarefas e cuidar da casa também. É uma sobrecarga enorme" (P2).

A suspensão das aulas e das terapias das crianças também sobrecarregaram as mães, já que estas se tornaram as responsáveis principais pela condução dessas atividades com a orientação dos profissionais:

"Fazer as tarefas de casa nunca foi fácil. Mas agora é pior. Fazer uma criança com dificuldade de concentração ficar parada para assistir aulas remotas é extremamente desgastante" (P6).

"A professora manda as tarefas pelo WhatsApp. Está muito difícil. Ela não está entendendo nada, não está acompanhando. [...] E sou eu quem tenho que dar um jeito"

"As terapeutas enviam materiais pra que a gente aplique em casa. Mas eu estou física e emocionalmente exausta demais para isso. Não é produtivo" (P8). 
A internalização dos papéis de gênero pelas próprias mulheres as leva a perceberem o pai como uma rede de apoio e não como corresponsável pelo cuidado da criança:

"A única rede de apoio que eu tenho no momento é o meu esposo. Ele só vem pra casa à noite quando consegue me ajudar" (P2).

"A gente está se separando. Então eu sou a única responsável por tudo mesmo. Agora, com esse isolamento, nem as visitas estão acontecendo" (P7).

As falas do único participante do gênero masculino, corrobora essas percepções. Suas respostas foram enfáticas a respeito das dificuldades, mas bastante superficiais acerca das estratégias de enfrentamento, reafirmando sua esposa como a responsável principal pelo cuidado, enquanto também ele se percebe como rede de apoio:

"A minha esposa é quem conduz essa parte. Eu fico como apoio, mas estou a postos pro que for preciso".

Além disso, ao contrário do observado nas falas femininas, para ele, o trabalho externo não agrega dificuldade, sendo inclusive desejado:

"O meu principal anseio é voltar ao trabalho, que é o que eu mais gosto"

A introjeção da responsabilidade faz com que as mães se sintam culpadas por não estarem conseguindo exercer na plenitude as funções demandadas, além de gerar adoecimento psíquico:

"A culpa é terrível. A gente que é mãe se cobra, por que sabe que o desenvolvimento da nossa criança depende principalmente da gente" (P10).

"Eu estou ansiosa, estressada, chorando por tudo. Eu só peço a Deus que tudo passe logo, pois tenho medo de que aconteça algo comigo, pois só tenho ela de filha e ninguém vai cuidar dela como eu" (P3).

As falas reafirmam a estrutura de poder político baseada no gênero e que se disfarça em sistema de diferença natural. Nestes sistemas, a mãe assume a condição identitária de única responsável pelos cuidados com os filhos, enquanto a paternidade, não demanda o mesmo dos homens (Zanello, 2020). Esses fatos foram magnificados durante a pandemia, ampliando a sobrecarga feminina e potencializando adoecimentos (Almeida et al., 2020).

Vale ressaltar que, além de todas as questões sexistas e patriarcais, as participantes convivem com as cobranças sociais que permeiam o exercício da maternagem de uma criança autista. Apesar de as primeiras Teorias Psicogênicas elaboradas sobre o autismo já terem sido descartadas, as construções discursivas que culpabilizam a mãe ainda são frequentes, contribuindo para seu sofrimento psíquico e auto-culpabilização (Lopes, 2019, 2020).

\subsection{Anseios Relacionados ao Processo Terapêutico}

Todas as mães participantes, bem como o pai, declararam temer retrocessos diante da interrupção das atividades escolares, pedagógicas e terapêuticas, bem como da limitação das atividades sociais:

"meu filho teve grande evolução com a terapia, mas agora sem fazer vai atrasar muito, né?" (P1).

"ele fala pouco, então a gente tenta estimular ao máximo, mas acaba tendo impacto o fato dele não está socializando" (P2).

Algumas mães perceberam que os filhos ficaram confortáveis após um tempo de isolamento, o que emergiu como motivo de apreensão:

"[o isolamento social] interfere muito [...] porque ele já não gosta de brincar com as crianças, e infelizmente não posso trabalhar isso com ele" 
"agora com a pandemia meu filho voltou a ter medo das pessoas, não quer brincar com ninguém" (P11).

"tenho medo que ele estranhe ainda mais as pessoas quando isso acabar e que ele sofra mais preconceito por isso" (P9).

"meu filho gosta de brincar com as outras crianças e sente falta delas" (P5).

" isolamento e a falta das terapias tem deixado ele mais irritado e agitado, por passar o dia todo em casa" (P15).

Uma das maiores apreensões das mães de crianças autistas é em relação ao estigma social que esses vivenciam diante das dificuldades de socialização, sendo compreensível o receio de retrocessos no atual contexto (Amorim et al., 2020; Colizzi et al., 2020). Vale ressaltar, contudo, que o paradigma da Neurodiversidade compreende o autismo como uma condição diferente de ser/estar no mundo, uma diferença neurológica, e não uma incapacidade (Baron-Cohen, 2017; Ortega, 2009). As dificuldades de socialização, portanto, devem ser trabalhadas a fim de favorecer o desenvolvimento da autonomia e nunca objetivando uma "normalização" (Baron-Cohen, 2017). Neste contexto, chama a atenção que nenhum dos informantes considerou o próprio ambiente familiar como espaço para trabalhar a socialização.

\subsection{Resiliência e religiosidade}

A pergunta sobre as estratégias desenvolvidas durante o período foi seguida frequentemente de um longo período de silêncio e pela reafirmação dos receios e incertezas anteriormente afirmados. Vale ressaltar que a pesquisa foi conduzida durante a primeira onda da pandemia, quando as informações ainda eram escassas e não havia indícios de que a vacinação estaria disponível em breve. Nesse contexto, a religiosidade foi evidenciada como principal fonte de conforto:

"pra amenizar tudo isso, eu procuro ler alguma coisa e rezo demais pra poder amenizar a angústia no coração. Estou pedindo a Deus bastante paciência e sabedoria. Só mesmo tendo muita fé em Deus pra enfrentar isso" (P1).

"A gente tenta se apegar a Deus, que é nossa maior força." (P6).

"mas isso vai passar em nome de Jesus, eu creio. A gente vai ficar bem" (P3).

O constructo resiliência pode ser compreendido como a capacidade das pessoas para superar, condições adversas que envolvam risco ao seu bem-estar (Amar et al., 2013). Nessa perspectiva, a resiliência de nossas informantes foi fortalecida pela religiosidade, que pode se fortalecer diante do sentimento de desamparo (Chaves \& Gil, 2015).

\section{Conclusões}

Os achados evidenciam que a pandemia e a necessidade de isolamento social rígido potencializaram desigualdades de gênero, culminando no desgaste físico, psíquico e emocional dessas mulheres. Atrelada a essas questões, emerge a preocupação com prejuízos no desenvolvimento dos filhos. Esses anseios, amplificam a auto responsabilização dessas mulheres, culminando em um sentimento de culpa que encontra amparo na religiosidade como principal estratégia de enfrentamento.

Considerando que partimos do paradigma da Neurodiversidade como lente teórica, consideramos como pressuposto que pais e mães podem falar apenas por si memos e não por seus filhos. Deste modo, esse recorte não abordou os efeitos da pandemia sobre pessoas autistas.

A utilização de abordagem qualitativa nesta pesquisa possibilitou uma percepção mais aprofundada da realidade dos participantes. A análise temática de conteúdo, por sua vez, permitiu a compreensão do fenômeno do ponto de vista das mães e do pai entrevistado. 
Consideramos como fragilidade desse estudo a participação de apenas um colaborador do gênero masculino, além da impossibilidade e um processo de observação não participante preliminar, diante do contexto sanitário vigente.

\section{Referências}

Almeida, M., Shrestha, A. D., Stojanac, D., \& Miller, L. J. (2020). The impact of the COVID-19 pandemic on women's mental health. Archives of Women's Mental Health, 23(6), 741-748. https://doi.org/10.1007/s00737-020-01092-2

Amar, J. A., González, M. M., \& Utria, L. U. (2013). Nuevo abordaje de la salud considerando la resiliencia. Revista Salud Uninorte, 29(1), 124-133. http://www.scielo.org.co/scielo.php?script=sci_arttext\&pid=S0120-55522013000100014

Amorim, R., Catarino, S., Miragaia, P., Ferreras, C., Viana, V., \& Guardiano, M. (2020). The impact of COVID-19 on children with autism spectrum disorder. Revista de Neurologia, 71(8), 285-291. https://doi.org/10.33588/RN.7108.2020381

Baron-Cohen, S. (2017). Editorial Perspective: Neurodiversity - a revolutionary concept for autism and psychiatry. In Journal of Child Psychology and Psychiatry and Allied Disciplines (Vol. 58, Issue 6, pp. 744-747). Blackwell Publishing Ltd. https://doi.org/10.1111/jcpp.12703

Bialer, M. (2015). A inclusão escolar nas autobiografias de autistas. Psicologia Escolar e Educacional, 19(3), 485-492. https://doi.org/10.1590/2175-3539/2015/0193876

Chaves, L. J., \& Gil, C. A. (2015). Older people's concepts of spirituality, related to aging and quality of life. Ciência \& Saúde Coletiva, 20(12), 3641-3652. https://www.scielosp.org/pdf/csc/v20n12/en_1413-8123-csc-20-12-3641.pdf

Colizzi, M., Sironi, E., Antonini, F., Ciceri, M. L., Bovo, C., \& Zoccante, L. (2020). Psychosocial and behavioral impact of COVID-19 in autism spectrum disorder: An online parent survey. Brain Sciences, 10(6). https://doi.org/10.3390/brainsci10060341

Courtenay, K., \& Perera, B. (2020). COVID-19 and people with intellectual disability: Impacts of a pandemic. Irish Journal of Psychological Medicine, 37(3), 231-236. https://doi.org/10.1017/ipm.2020.45

Fontanella, B. J. B., Luchesi, B. M., Saidel, M. G. B., Ricas, J., Turato, E. R., \& Melo, D. G. (2011) Amostragem em pesquisas qualitativas: Proposta de procedimentos para constatar saturação teórica. Cadernos de Saude Publica, 27(2), 389-394. https://doi.org/10.1590/s0102$311 \times 2011000200020$

Lopes, B. A. (2019). Não Existe Mãe-Geladeira Uma análise feminista da construção do ativismo de mães de autistas no Brasil [Universidade Estadual de Ponta Grossa]. http://tede2.uepg.br/jspui/handle/prefix/2922

Lopes, B. A. (2020). Autism, maternal narratives and activism from 1970to 2008. In Revista Brasileira de Educacao Especial (Vol. 26, Issue 3, pp. 377-392). Associacao Brasileira de Pesquisadores em Educacao Especial. https://doi.org/10.1590/1980-54702020v26e0169

Lord, C., Elsabbagh, M., Baird, G., \& Veenstra-Vanderweele, J. (2018). Autism spectrum disorder. In The Lancet (Vol. 392, Issue 10146, pp. 508-520). Lancet Publishing Group. https://doi.org/10.1016/S0140-6736(18)31129-2

Minayo, M. C. (2014). O desafio do conhecimento: pesquisa qualitativa em saúde. São Paulo: HUCITEC (1a). Hucitec.

Ortega, F. (2009). Deficiência, autismo e neurodiversidade. Ciência \& Saúde Coletiv, 14(1), 67-77. https://scielosp.org/pdf/csc/2009.v14n1/67-77/pt

Lei No 12.764, de 27 de deazembro 2012, (2012) (Presidência da República, Casa Civil, \& Subchefia para Assuntos Jurídicos). http://www.planalto.gov.br/ccivil_03/_ato2011-2014/2012/lei/12764.htm

Vinuto, J. (2014). A amostragem em bola de neve na pesquisa qualitativa. Tematicas, 22(44), 203-220. https://doi.org/10.20396/tematicas.v22i44.10977

WHO (2021). COVID-19 Strategic Preparedness and Response Plan (SPRP 2021) (World Health Organization, Ed.). World Health Organization. https://www.who.int/publications/i/item/WHO-WHE2021.02

Zanello, V. (2020). Saúde Mental, Gênero e Dispositivos: Cultura e Processos de Subjetivação - Valeska Zanello - Google Livros (1a). Editora Appris. 